\title{
Physician spending and subsequent risk of malpractice claims: observational study
}

\author{
Anupam B Jena, ${ }^{1,2}$ Lena Schoemaker, ${ }^{3}$ Jay Bhattacharya, ${ }^{2,3}$ Seth A Seabury ${ }^{2,4}$
}

'Department of Health Care

Policy, Harvard Medical School,

Boston, MA 02115, USA; and

Massachusetts General

Hospital, Boston, MA, USA

${ }^{2}$ National Bureau of Economic

Research, Cambridge, MA, USA

${ }^{3}$ Center for Primary Care and

Outcomes Research, Stanford

University School of Medicine,

Stanford, CA, USA

${ }^{4}$ Department of Emergency

Medicine and Leonard D

Schaeffer Center for Health

Policy and Economics,

University of Southern

California, Los Angeles, CA, USA

Correspondence to: A B Jena jena@hcp.med.harvard.edu

Additional material is published online only. To view please visit

the journal online (http://dx.doi. org/10.1136/bmj.h5516)

Cite this as: BMJ 2015;351:h5516 doi: 10.1136/bmj.h5516

Accepted: 5 October 2015

\section{ABSTRACT}

\section{STUDY QUESTION}

Is a higher use of resources by physicians associated with a reduced risk of malpractice claims?

\section{METHODS}

Using data on nearly all admissions to acute care hospitals in Florida during 2000-09 linked to malpractice history of the attending physician, this study investigated whether physicians in seven specialties with higher average hospital charges in a year were less likely to face an allegation of malpractice in the following year, adjusting for patient characteristics, comorbidities, and diagnosis. To provide clinical context, the study focused on obstetrics, where the choice of caesarean deliveries are suggested to be influenced by defensive medicine, and whether obstetricians with higher adjusted caesarean rates in a year had fewer alleged malpractice incidents the following year.

\section{STUDY ANSWER AND LIMITATIONS}

The data included 24637 physicians, 154725 physician years, and 18352391 hospital admissions; 4342 malpractice claims were made against physicians (2.8\% per physician year). Across specialties, greater average spending by physicians was associated with reduced risk of incurring a malpractice claim. For example, among internists, the probability of experiencing an alleged malpractice incident in the following year ranged from 1.5\% (95\% confidence interval $1.2 \%$ to $1.7 \%$ ) in the bottom spending fifth (\$19725 (£12 800; €17 400) per hospital admission) to $0.3 \%(0.2 \%$ to $0.5 \%)$ in the top fifth (\$39379 per hospital admission). In six of the specialties, a greater use of resources was associated with statistically significantly lower subsequent rates of alleged malpractice incidents. A principal limitation of this study is that information on illness severity was

\section{WHAT IS ALREADY KNOWN ON THIS TOPIC}

Defensive medicine is defined as medical care provided to patients solely to reduce the threat of malpractice liability rather than to further diagnosis or treatment

In the United States most physicians report practicing defensive medicine to reduce malpractice liability

However, no evidence exists on the overall question of whether higher levels of resource use are associated with a reduced risk of malpractice claims

\section{WHAT THIS STUDY ADDS}

A higher use of resources by US physicians in acute care hospitals in Florida during 2000-09 was associated with fewer malpractice claims

Also, focusing on a specific example of caesarean deliveries (argued to be influenced by defensive medicine), obstetricians with higher risk adjusted caesarean rates in a year had fewer alleged malpractice incidents the following year

lacking. It is also uncertain whether higher spending is defensively motivated.

\section{WHAT THIS STUDY ADDS}

Within specialty and after adjustment for patient characteristics, higher resource use by physicians is associated with fewer malpractice claims.

\section{FUNDING, COMPETING INTERESTS, DATA SHARING} This study was supported by the Office of the Director, National Institutes of Health (grant 1DP50D017897-01 to ABJ) and National Institute of Aging (R37 AG036791 to JB). The authors have no competing interests or additional data to share.

\section{Introduction}

Critics of the US malpractice system often note that it promotes defensive medicine-defined as medical care provided to patients solely to reduce the threat of malpractice liability rather than to further diagnosis or treatment. Physicians report defensive medicine as a major contributor to healthcare costs, and commonly argue that they must practice defensively to reduce malpractice liability ${ }^{1-5}$ For instance, among physicians practicing in high risk specialties in Pennsylvania during a malpractice crisis, more than $90 \%$ reported sometimes or often practicing defensive medicine. ${ }^{1}$ In Massachusetts, more than $80 \%$ of physicians report practicing defensive medicine, with a reported $20 \%$ to $30 \%$ of imaging studies and $13 \%$ of hospital admissions being defensively motivated. ${ }^{6}$ In a national survey of US physicians, over $60 \%$ reported ordering diagnostic tests or consultations solely to reduce the threat of liability. ${ }^{3}$ Several economic studies confirm the presence of defensive medicine among US physicians, ${ }^{7-12}$ although estimates of its size are of considerable debate. ${ }^{31314}$ Concerns by physicians about malpractice liability and defensive medicine are not only limited to the United States. For example, in a survey of UK hospital doctors, $78 \%$ reported practicing defensive medicine, with the ordering of tests and unnecessary referral to other specialties cited as the most common examples. ${ }^{15}$

Despite widespread agreement that physicians practice defensive medicine to reduce malpractice liability, there are no studies of whether greater resource use by physicians, whether it is defensively motivated or not, is associated with reduced claims for malpractice. This lack of evidence is surprising, given that defensive medicine is premised on greater resource use reducing malpractice liability. The fact that most physicians practice at least some defensive medicine raises the question of whether a majority of physicians could be incorrect in believing that greater resource use can deter liability. 
There are reasons to believe that the level of resource use provided by physicians bears little relation to risk of liability. Studies suggest that a substantial fraction of malpractice claims stem from failures in physician-patient communication. ${ }^{16-19}$ Furthermore, though diagnostic errors are the leading cause of malpractice claims in the US and several other countries, ${ }^{20-22}$ these are usually attributed to cognitive or system errors rather than to the level of resource use..$^{23-25}$ The majority of adverse clinical events also do not result in malpractice claims, and a substantial proportion of claims involve no medical error, both of which suggest substantial idiosyncrasy in malpractice. ${ }^{26-29}$ Finally, although few studies have specifically studied the association between resource use and medical errors, several studies have questioned whether greater resource use improves clinical outcomes more broadly. ${ }^{30-34}$ Each of these considerations attenuate the relation between malpractice claims and the level of resource use.

We linked data on nearly all hospital admissions in Florida between 2000 and 2009 to the malpractice history of each attending physician of record to investigate whether physicians who provide more costly care are less likely to face malpractice claims. Adjusting for differences in patient characteristics across physicians and analyzing physician specialties separately, we examined the association between a physician's average hospital costs in a given year and the probability of a malpractice claim stemming from an incident occurring in the following year. To provide clinical context, we also studied whether the average risk adjusted rate of caesarean deliveries among obstetricians-a decision often argued to reflect defensive medicine-was associated with a lower risk of subsequent malpractice. ${ }^{1135-38}$ In both instances, our motivation was to explore whether greater resource use, defensively motivated or not, is associated with reduced malpractice claims.

\section{Methods}

\section{Data sources}

We obtained data from the Florida Agency for Health Care Administration on all hospital discharges from all non-state, non-federal Florida acute care hospitals during 2000-09. Data included patient age, sex, race, zip code of residence, year of hospital admission, ICD-9 (international classification of diseases, ninth revision) codes for principal and secondary diagnoses and procedures, discharge diagnosis related group, and total hospital charges. Each record also included the Florida license number of the attending physician of record for the hospital admission.

We also obtained data from the Florida Office of Insurance Regulation on all closed malpractice claims against Florida physicians with active medical licenses reported during the study period. By Florida law, all liability insurers and self insured healthcare providers are required to report claims for personal injury damages alleged to have occurred as a result of provider error, omission, or negligence, as well as indemnity payments. All claims are reported irrespective of whether they were settled or tried in court. Each closed claim record included the license number of the physician involved, whether an indemnity payment was made, and, if so, payment size, and dates of alleged injury, claim filing, and claim closure. Claims closed after December 2013 were unavailable. On average, however, malpractice claims are closed within four years of incident date, ${ }^{39}$ allowing us to capture the majority of claims arising from clinical encounters that occurred in the last year of our study period, 2009.

Finally, we obtained data on physician specialty from publicly available practitioner profiles maintained by the Florida Agency for Health Care Administration.

\section{Outcome measure}

Our primary outcome was a binary variable for whether a physician was involved in an incident in a given year that resulted in a subsequent malpractice claim filed against the physician. For example, claims filed for incidents occurring in 2005 were attributed to the relevant physicians in 2005, rather than the year in which the claim was filed or it was closed, which could be several years after the event. ${ }^{39}$ We attributed claims according to incident date rather than claim date because our primary interest was to examine whether the average intensity of care provided by a physician in a given year (for example, 2004) was associated with future malpractice liability stemming from clinical care provided in the subsequent year (that is, 2005). We did not compare spending in the current year with the probability of a claim in that same year because of concerns about reverse causality (the presence of an event resulting in a malpractice claim in a year could alter that physician's practice patterns). Note that our approach assumes that a physician's spending in a given year is a reliable predictor of a physician's overall spending pattern and not idiosyncratic from year to year-that is, that the relative intensity of physician practice styles persists over time. To confirm this, we demonstrated that physician spending in one year is highly positively correlated with spending in the next year (see supplementary eTable 1), suggesting that physician spending patterns are more systematic than idiosyncratic.

\section{Physician resource use measures}

We examined the association between the use of resources by physicians and subsequent malpractice claims by testing whether, within a specialty, physicians who tend to provide more costly care (after adjustment for clinical differences between patients) are more or less likely to face a future claim. We created two measures of intensity of care provided by physicians, one general and one clinically specific.

Our first measure was total hospital charges associated with patients treated by a given physician in a given year, averaged across all patients treated by that physician in that year and adjusted for patient personal and clinical characteristics. Although several physicians may be involved in the care of a hospital inpatient, we attributed all charges to the attending physician of record, intending to measure the overall approach of that physician toward hospital care. ${ }^{40}$ 
Specifically, though multiple providers may be involved in the care of a single patient admitted to a hospital, the attending physician is classically responsible for the various day to day evaluation and management decisions for a given patient, which include diagnostic and laboratory testing, requesting assistance of specialist physicians and other providers, and determining date of discharge, all of which contribute to hospital costs.

We accounted for differences in patient characteristics and admission diagnoses between physicians by estimating a patient level multivariable linear model of total hospital charges during the hospital stay as a function of patient age, sex, race, diagnosis related group, indicator variables for Charlson-Deyo comorbid conditions, and year and physician indicators. We then used the results of the model to compute the average, adjusted cost of a hospital admission associated with each physician in a given year. Resource use and malpractice risk vary considerably by specialty, so we estimated separate models for internal medicine, internal medicine subspecialty, family medicine, pediatrics, general surgery, surgical subspecialty, and obstetrics and gynecology.

Given that the average hospital cost for a physician is a general measure of resource use, our second resource use measure was more clinically specific-namely, the risk adjusted rate of caesarean childbirths among obstetricians. Compared with our general measure of overall resource use, caesarean rates offer a well studied and clinically specific example of how physicians respond to malpractice liability. For instance, among 26 specialties in a large US study, obstetrics ranked fourth in the rate of paid malpractice claims and third in the average size of malpractice payments. ${ }^{41}$ Geographic areas with greater pressure for malpractice have been associated with higher caesarean delivery rates, whereas state tort reforms that have a lower pressure for malpractice have been associated with decreased caesarean rates. ${ }^{1136-39}$ Moreover, US caesarean delivery rates grew by nearly $60 \%$ from 1996 to 2013 (20.7\% of all deliveries in $1996 v 32.7 \%$ in 2013) coincident with several malpractice crises. ${ }^{42}$

We tested whether obstetricians with a greater propensity to perform caesarean deliveries in a given year had lower malpractice claims in the following year. Among 1518702 admissions for childbirth (identified by diagnosis related group codes 370-371 for caesarean delivery and 372-373 for vaginal delivery), we constructed adjusted physician year level caesarean rates by estimating a patient level logistic model of caesarean delivery as a function of mother's age, race, year indicators, and physician indicators. To isolate differences in the underlying propensity of obstetricians to perform caesarean sections in areas where they had more clinical discretion, we excluded women with clinical contraindications to vaginal delivery endorsed by the joint commission (for example, fetal distress, breech presentation, previous caesarean). 43

For both the spending and the caesarean measures we applied bayesian shrinkage to adjust unreliable estimates (that is, observations for physicians who billed for few patients during a year) toward the specialty-year specific mean and to improve ranking of individual physicians in terms of their intensity of resource use. ${ }^{4445}$ This approach accounts for noise in the measured variables and provides a more accurate measure of the relation between physician spending levels and the outcome variables than do simple averages.

\section{Statistical analysis}

We used two approaches to analyze whether our measures of physician resource use in a year were associated with alleged malpractice incidents in the following year. Firstly, within specialty, we classified physician years into fifths of adjusted spending and then computed average alleged malpractice incident rates in the following year according to adjusted spending fifth. Similarly, for obstetricians we computed average malpractice incident rates according to fifth of adjusted caesarean rates. Observations in fifths were at the physician year level. We categorized physicians into fifths of resource use rather than using a continuous measure, to allow for a non-linear relation between resource use and probability of malpractice incident in the following year.

Additionally, we estimated linear regression models with physician fixed effects to eliminate unobservable, time invariant differences in physicians associated with both higher average intensity of care and malpractice risk of physicians. These could include differences in average patient population even after adjustment for comorbidities and diagnoses, or they could include plausibly fixed physician characteristics such as clinical knowledge or communication skills. This within physician analysis estimated the effect of use of healthcare resources by physicians on subsequent malpractice claims by studying changes in utilization and malpractice claims within the same physician over time. In all analyses, we weighted observations at the physician year level according to the number of patients in each physician year.

\section{Sensitivity analyses}

We conducted several sensitivity analyses to verify that model or specification choice did not drive our findings. Firstly, it is possible that average resource use by physicians and the probability of claims for malpractice will differ between non-teaching and teaching hospitals or between for profit and not for profit hospitals, which could confound our analysis. We addressed this problem for each specialty by estimating the association between adjusted physician level spending and subsequent malpractice incidents, including hospital specific fixed effects. For each specialty, this analysis therefore compared rates of subsequent malpractice incidents between high spending and low spending physicians within the same hospital. Secondly, our baseline analysis estimated the association between malpractice incidents and one year lagged physician spending (categorized into fifths). We assessed the sensitivity of our findings instead using a continuous measure of physician 
spending, which was separately included in the model in lags of one year, two years, and three years. Thirdly, we based our estimates of physician spending on hospital admission data from 2000 to 2009, and closed malpractice claims data were available until December 2013. We therefore assumed that four or five years after an alleged malpractice incident would be enough for most malpractice claims to be closed for physicians for whom we had spending data in 2009 (for example, physicians with a malpractice incident in January 2009 would have nearly five years for a claim to be closed to appear in our data). We assessed the sensitivity of our findings to this assumption by restricting our analysis to data on hospital admissions from 2000 to 2008, thereby allowing five or six years' follow-up for malpractice claims to be closed and therefore appear in our data. Moreover, we examined whether our findings were sensitive to defining malpractice incidents only among claims closed within a period of six years.

\section{Patient involvement}

No patients were involved in setting the research question or the outcome measures, nor were they involved in the design and implementation of the study. There are no plans to involve patients in dissemination of the results.

\section{Results}

\section{Characteristics of study sample}

Our data included 24637 physicians and 154725 physician years linked to nearly 19 million hospital discharges. The mean number of hospital admissions for each physician year varied by specialty and was largest in obstetrics and gynecology and in internal medicine (table 1). Overall, 4342 malpractice claims were filed against physicians (claim rate $2.8 \%$ per physician year). Malpractice rates varied across specialty consistently with previous studies, ${ }^{41}{ }^{46}$ ranging from $1.6 \%$ per physician year in pediatrics to $4.1 \%$ per physician year in general surgery and obstetrics and gynecology.

\section{Hospital charges and malpractice claims}

Across all specialties there was a negative association between the fifth of risk adjusted average spending for a given physician year and the probability of facing an alleged malpractice incident in the subsequent year (table 2). For example, in internal medicine, mean risk adjusted hospital spending per physician ranged from $\$ 19725$ (£12800; €17 400) for each hospital admission in the bottom fifth of physician years to $\$ 39379$ for each hospital stay in the top fifth, whereas the probability of experiencing an alleged malpractice incident in the subsequent year ranged from 1.5\% (95\% confidence interval $1.2 \%$ to $1.7 \%$ ) in the bottom fifth of spending to $0.3 \%(0.2 \%$ to $0.5 \%)$ in the top fifth. Similarly, in obstetrics and gynecology the probability of experiencing an alleged malpractice incident in the subsequent year ranged from $1.9 \%$ (1.3\% to $2.4 \%$ ) in the bottom fifth of adjusted physician year spending to $0.4 \%(0.1 \%$ to $0.8 \%$ ) in the top fifth.

In analyses that relied on variation in risk adjusted spending within the same physician over time (that is, within physician analysis), greater physician spending in a given year continued to be negatively correlated with the probability of facing an alleged malpractice incident in the subsequent year, across specialties (table 3). The relation was statistically significant at the $5 \%$ level or better for all specialties except family medicine.

\section{Caesarean deliveries and malpractice claims}

Our data included 1518702 deliveries (224850 were caesarean, $14.8 \%$ ) performed by 1625 obstetricians across 10358 physician years. In total, 496 malpractice claims were filed against these physicians (rate $4.8 \%$ for each physician year; table 4).

Increasing average risk adjusted caesarean rates for each obstetrician year was associated with decreases in the probability that an obstetrician experienced an alleged malpractice incident in the subsequent year (table 5). For example, the average adjusted caesarean rate for each obstetrician increased from 5.1\% in the bottom fifth of obstetrician years to $31.6 \%$ in the top

\begin{tabular}{|c|c|c|c|c|c|c|c|}
\hline Characteristics & $\begin{array}{l}\text { Internal } \\
\text { medicine }\end{array}$ & $\begin{array}{l}\text { Internal medicine } \\
\text { subspecialty }\end{array}$ & $\begin{array}{l}\text { Family } \\
\text { Medicine }\end{array}$ & Pediatrics & $\begin{array}{l}\text { General } \\
\text { surgery }\end{array}$ & $\begin{array}{l}\text { Surgical } \\
\text { subspecialty }\end{array}$ & $\begin{array}{l}\text { Obstetrics and } \\
\text { gynecology }\end{array}$ \\
\hline No of physicians & 8654 & 2745 & 2519 & 3649 & 3319 & 1812 & 1939 \\
\hline No of physician years & 53984 & 18138 & 13163 & 22820 & 21404 & 11874 & 13342 \\
\hline No of hospital admissions & 7682304 & 1505529 & 1412864 & 2740541 & 1863745 & 998797 & 2148611 \\
\hline No of hospital admissions per physician year & 142 & 83 & 107 & 120 & 87 & 84 & 161 \\
\hline No of malpractice claims & 1442 & 501 & 246 & 359 & 869 & 385 & 540 \\
\hline No of malpractice claims per 100 physician years & 2.7 & 2.8 & 1.9 & 1.6 & 4.1 & 3.2 & 4.0 \\
\hline \multicolumn{8}{|c|}{ Mean adjusted annual charges per hospital admission (\$):* } \\
\hline Physicians with a malpractice claim & 25775 & 30972 & 18653 & 11034 & 31474 & 33561 & 10601 \\
\hline Physicians without a malpractice claim & 28636 & 34621 & 22566 & 12689 & 36701 & 40804 & 12656 \\
\hline P value for differencet & $<0.001$ & $<0.001$ & 0.02 & $<0.001$ & $<0.001$ & $<0.001$ & $<0.001$ \\
\hline
\end{tabular}

${ }^{\star}$ Adjusted for patient age, sex, race, comorbid conditions, diagnosis related group, county fixed effects, and year. Charges for physicians with a malpractice claim reflect the mean hospital

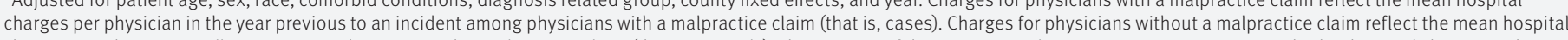
charges per physician in all years among physicians with a malpractice claim (that is, controls). The purpose of this case-control comparison was to examine whether hospital charges in the year previous to an incident that led to malpractice (among physicians who faced a malpractice claim) differed from average annual hospital charges for physicians who were not sued. tDifference in means between cases and controls. 


\begin{tabular}{|c|c|c|c|c|c|}
\hline \multirow[b]{2}{*}{ Specialty } & \multicolumn{5}{|c|}{ Fifth of adjusted hospital spending* } \\
\hline & First (lowest) & Second & Third & Fourth & Fifth (highest) \\
\hline \multicolumn{6}{|l|}{ Internal medicine: } \\
\hline Adjusted hospital spending (\$) & 19725 & 25392 & 29926 & 34133 & 39379 \\
\hline Malpractice claim rate $(\%, 95 \% \mathrm{Cl})$ & $1.5(1.2$ to 1.7$)$ & $1.1(0.9$ to 1.3$)$ & 0.8 (0.6 to 0.9$)$ & $0.6(0.4$ to 0.8$)$ & $0.3(0.2$ to 0.5$)$ \\
\hline \multicolumn{6}{|l|}{ Internal medicine subspecialty: } \\
\hline Adjusted hospital spending (\$) & 23626 & 32573 & 36165 & 41651 & 46654 \\
\hline Malpractice claim rate $(\%, 95 \% \mathrm{Cl})$ & 1.7 (1.3 to 2.2$)$ & $1.4(1.0$ to 1.8$)$ & $0.6(0.4$ to 0.9$)$ & 0.7 (0.4 to 1.0$)$ & $0.2(0.0$ to 0.5$)$ \\
\hline \multicolumn{6}{|l|}{ Family medicine: } \\
\hline Adjusted hospital spending (\$) & 13809 & 17357 & 23533 & 28283 & 35305 \\
\hline Malpractice claim rate $(\%, 95 \% \mathrm{Cl})$ & $0.5(0.2$ to 0.8$)$ & $0.5(0.2$ to 0.8$)$ & $0.3(0.1$ to 0.6$)$ & $0.0(0.0$ to 0.0$)$ & $0.2(-0.1$ to 0.4$)$ \\
\hline \multicolumn{6}{|l|}{ Pediatrics: } \\
\hline Adjusted hospital spending (\$) & 9121 & 10924 & 12177 & 14877 & 19916 \\
\hline Malpractice claim rate $(\%, 95 \% \mathrm{Cl})$ & 0.7 (0.4 to 0.9$)$ & $0.2(0.1$ to 0.4$)$ & $0.3(0.1$ to 0.5$)$ & $0.1(0.0$ to 0.2$)$ & $0.1(0.0$ to 0.3$)$ \\
\hline \multicolumn{6}{|l|}{ General surgery: } \\
\hline Adjusted hospital spending (\$) & 25141 & 31542 & 38848 & 43877 & 51987 \\
\hline Malpractice claim rate $(\%, 95 \% \mathrm{Cl})$ & 2.3 (1.8 to 2.7$)$ & 0.9 (0.6 to 1.2) & $0.8(0.5$ to 1.1$)$ & $0.6(0.3$ to 0.8$)$ & $0.4(0.1$ to 0.6$)$ \\
\hline \multicolumn{6}{|l|}{ Surgical subspecialty: } \\
\hline Adjusted hospital spending (\$) & 26979 & 34316 & 40571 & 51959 & 61907 \\
\hline Malpractice claim rate $(\%, 95 \% \mathrm{Cl})$ & $1.7(1.1$ to 2.2$)$ & $0.9(0.5$ to 1.3$)$ & $0.7(0.3$ to 1.0$)$ & $0.3(0.1$ to 0.5$)$ & $0.1(-0.1$ to 0.3$)$ \\
\hline \multicolumn{6}{|l|}{ Obstetrics and gynecology: } \\
\hline Adjusted hospital spending (\$) & 8653 & 11094 & 13101 & 15213 & 18162 \\
\hline Malpractice claim rate $(\%, 95 \% \mathrm{Cl})$ & 1.9 (1.3 to 2.4$)$ & $1.1(0.7$ to 1.5$)$ & 0.5 (0.2 to 0.8$)$ & $0.2(0.0$ to 0.3$)$ & 0.4 (0.1 to 0.8$)$ \\
\hline
\end{tabular}

$\$ 1.00$ (f0.65; €0.88).

*Computed at physician year level, within specialty. Indicator variables were created for whether a physician experienced an adverse incident in the following year that ultimately resulted in a malpractice claim. The mean malpractice claim rate per spending fifth was computed by averaging this indicator variable across all physician years in a spending fifth.

fifth, whereas the probability an obstetrician experienced an alleged malpractice incident in the subsequent year decreased from 5.7\% (95\% confidence interval $4.6 \%$ to $6.8 \%$ ) in the bottom fifth of caesarean delivery rates to $2.7 \%$ (1.9\% to $3.6 \%)$ in the top fifth. In within physician analyses, which relied on variation in risk adjusted caesarean rates within the same obstetrician over time, greater caesarean rates continued to be negatively correlated with the probability of facing an alleged malpractice incident in the subsequent year (increased risk adjusted caesarean rate from the bottom fifth to the top fifth was associated with a -1.5 percentage point ( $95 \%$ confidence interval to -3.6 to -0.6 ) change in malpractice claims in the subsequent year).

\begin{tabular}{|c|c|c|}
\hline Specialty & $\begin{array}{l}\text { Absolute } \% \text { change in malpractice } \\
\text { claim rate* }(95 \% \mathrm{Cl})\end{array}$ & P valuet \\
\hline Internal medicine & $-2.1(-3.4$ to -0.8$)$ & 0.001 \\
\hline Internal medicine subspecialty & $-2.4(-4.7$ to -0.1$)$ & 0.04 \\
\hline Family medicine & $-1.2(-3.0$ to 0.6$)$ & 0.18 \\
\hline Pediatrics & $-1.3(-2.1$ to -0.4$)$ & 0.003 \\
\hline General surgery & $-3.4(-4.6$ to -2.1$)$ & $<0.001$ \\
\hline Surgical subspecialty & $-1.9(-3.0$ to -0.9$)$ & $<0.001$ \\
\hline Obstetrics and gynecology & $-1.3(-2.3$ to -0.4$)$ & 0.01 \\
\hline \multicolumn{3}{|c|}{$\begin{array}{l}\text { Table reports effect of increasing physician hospital spending from bottom fifth to top fifth on the probability a } \\
\text { physician experiences an event that leads to a subsequent malpractice claim. The model was estimated with } \\
\text { physician fixed effects (that is, a within physician analysis) and therefore accounted for the possibility that within } \\
\text { a specialty and even after adjustment for patient case mix and diagnosis related group, unobserved patient } \\
\text { characteristics may be associated with both higher use of healthcare resources by physicians and risk of } \\
\text { malpractice claims. The model estimated the effect of physician spending on subsequent malpractice claims by } \\
\text { studying changes in spending and malpractice claims within physicians over time. } \\
\text { *Associated with increase in physician spending from bottom to top fifth. } \\
\text { †Two sided } t \text { tests. }\end{array}$} \\
\hline
\end{tabular}

\section{Sensitivity analyses}

Our findings were robust across the different sensitivity analyses, including the estimation of models with hospital specific fixed effects to account for the possibility that average resource use and malpractice claims may vary systematically across different hospital types (see supplementary eTable 2); the estimation of models with continuous rather than categorical measures of physician spending as well as two year and three year lagged spending rather than one year lagged spending (see supplementary eTable 3); the estimation of models using data on hospital admissions from 2000 to 2008, thereby allowing five or six years of follow-up for malpractice claims to be closed and therefore appear in our data (see supplementary eTable 4); and relatedly, the estimation of models in which malpractice incidents were defined only among claims closed within a six year period (see supplementary eTable 5).

\section{Discussion}

Despite evidence that many physicians practice defensive medicine to reduce the risk of malpractice claims, ${ }^{1-3}$ no evidence exists on the broader question of whether a greater use of resources by physicians is associated with a reduced risk of such claims. We investigated the association between average resource use by physicians and subsequent malpractice claims. In six of seven specialties, we found that greater resource use was associated with statistically significantly lower subsequent rates of alleged malpractice incidents. For example, internists in the highest fifth of patient risk adjusted resource use were less than half as likely to face a future malpractice claim compared with those in the lowest fifth. Among obstetricians, those with higher 


\begin{tabular}{|c|c|}
\hline Characteristics & Obstetricians involved in deliveries \\
\hline No of physicians & 1625 \\
\hline No of physician years & 10358 \\
\hline No of deliveries (caesarean and vaginal) & 1518702 \\
\hline No of deliveries per physician year & 147 \\
\hline No of caesarean deliveries & 224850 \\
\hline Mean caesarean delivery rate (\%) & 14.8 \\
\hline No of malpractice claims & 496 \\
\hline No of malpractice claims per obstetrician year (\%) & 4.8 \\
\hline \multicolumn{2}{|l|}{ Mean adjusted caesarean rate per obstetrician (\%):* } \\
\hline Physicians with a malpractice claim & 13.7 \\
\hline Physicians without a malpractice claims & 15.2 \\
\hline Pvalue for differencet & $<0.001$ \\
\hline \multicolumn{2}{|c|}{$\begin{array}{l}\text { *Constructed by estimating a patient level logistic model of caesarean delivery as a function of mother's age, } \\
\text { race, year, and county fixed effects, and obstetrician indicators. Deliveries that involved clinical contraindications } \\
\text { to vaginal delivery (for example, fetal distress, breech presentation, previous caesarean) were excluded. } \\
\text { Caesarean rates for obstetricians with a malpractice claim reflect the mean rate per obstetrician in the year } \\
\text { previous to an incident among physicians with a malpractice claim (that is, cases). Caesarean rates for } \\
\text { obstetricians without a malpractice claim reflect the mean rate per obstetricians in all years among obstetricians } \\
\text { with a malpractice claim (that is, controls). } \\
\text { tDifference in means between cases and controls. }\end{array}$} \\
\hline
\end{tabular}

caesarean rates-a procedure sometimes considered to be defensively motivated-had lower subsequent rates of alleged malpractice. These relations held even when we adjusted for patient characteristics and accounted for time invariant physician characteristics such as patient mix, clinical skills, or communication skills. Within family medicine, higher spending physicians had statistically insignificant lower rates of subsequent malpractice claims, which may reflect a combination of relatively low malpractice claim rates overall and relatively fewer physicians compared with other specialties.

\section{Policy implications}

The implications of our findings for understanding the relation between resource use and subsequent malpractice liability depend on the mechanism through which higher resource use is associated with fewer claims. If higher spending is motivated by concerns about malpractice but is associated with fewer errors and therefore lower malpractice claims, then this spending would be considered defensively motivated but may not be wasteful because errors are lower. A comparison of the costs of additional resource use and the value of reduced errors would be needed to determine whether this defensively motivated care was socially wasteful (that is, classified as defensive medicine) or instead reflects socially beneficial deterrence (that is, the costs of additional resource use are outweighed by the value of reduced errors). If, in contrast, greater resource use is not associated with fewer errors and adds no other clinical benefit, then this additional spending could be considered wasteful, whether defensively motivated or not. In this latter case, the potential ability of physicians to reduce malpractice claims with increased spending would provide a strong incentive to practice defensively and therefore provide costly medical care with no clinical benefit. Moreover, physicians themselves do not generally bear the costs of additional healthcare spending (with the exception of capitated payment contracts) but do benefit from reduced liability associated with greater spending. The misalignment of benefits and costs to physicians may make greater healthcare spending attractive at the physician level although possibly inefficient at the societal level.

Without evidence on rates of errors associated with greater resource use, we cannot definitively conclude that defensive medicine-as it is traditionally definedreduces the number of malpractice claims. However, our findings still suggest that greater resource use is associated with fewer claims, which is consistent with physician beliefs that higher resource use, more generally, is associated with reduced liability of malpractice. ${ }^{1-5}$ There are multiple channels through which such a relation could operate. More frequent consultations and increased diagnostic testing could in theory reduce diagnostic errors, which are the leading cause of malpractice claims. ${ }^{20}$ Similarly, greater spending may result in fewer adverse events and therefore fewer malpractice claims. For instance, in some studies greater hospital spending has been associated with improved survival in several acute medical and surgical conditions, although to our knowledge no evidence exists at the physician level. ${ }^{47}$ Moreover, there is some evidence that improvements in process measures of quality are associated with reductions in malpractice claims ${ }^{48}$-our findings could be partly explained by the extent to which higher spending physicians are able to achieve better process measures of quality. Alternatively, more care could either foster a closer relationship between physician and patient or create the perception among patients that treatment was exhaustive, both of which may make patients less likely to file suit in cases where adverse events ultimately occurred. Finally, if judges or juries perceive more intensive care to imply more thorough care, this may reduce the ability of attorneys to successfully win litigation.

Despite our findings, the level of resource use provided by physicians is not the only factor that could influence malpractice claims and is perhaps not the most important. Several studies suggest that many

\begin{tabular}{|c|c|c|c|c|c|}
\hline \multirow[b]{2}{*}{ Variables } & \multicolumn{5}{|c|}{ Fifth of adjusted caesarean rate* } \\
\hline & First (lowest) & Second & Third & Fourth & Fifth (highest) \\
\hline Adjusted caesarean rate (\% of all deliveries) & 5.1 & 10.8 & 15.0 & 19.6 & 31.6 \\
\hline Malpractice suit rate $(\%, 95 \% \mathrm{Cl})$ & $5.7(4.6$ to 6.8$)$ & $5.1(4.1$ to 6.1$)$ & $4.7(3.7$ to 5.6$)$ & $3.3(2.5$ to 4.1$)$ & 2.7 (1.9 to 3.6$)$ \\
\hline
\end{tabular}


malpractice claims originate from failures in physician-patient relationships rather than in diagnostic or treatment failures alone. ${ }^{16-19}$ Malpractice also often involves errors of both omission and commission (that is, many adverse events do not result in lawsuits and many lawsuits do not involve a medical error). ${ }^{26-29}$ Malpractice liability may therefore also involve an idiosyncratic component that cannot be modified by decisions about broad levels of care chosen by physicians. However, it is possible that dealing with these issues could also alleviate incentives for defensive medicine simply by reducing the overall level of malpractice risk.

\section{Comparisons with other studies}

Although we studied healthcare spending and malpractice liability among US physicians, our findings have relevance internationally, with several non-US based studies demonstrating the importance of malpractice liability in shaping decisions made by physicians. For example, in a recent survey of UK hospital doctors, $78 \%$ reported practicing defensive medicine. ${ }^{15}$ In a 1994 survey of UK general practitioners, $98 \%$ of those surveyed reported practicing some form of defensive medicine, including increased diagnostic testing $(60 \%)$, increased follow-up (63\%), greater referrals to specialists (64\%), prescription of unnecessary drugs (29\%), and more detailed clinical documentation (90\%). ${ }^{49}$ Similar estimates were noted in a follow-up study by the same author. ${ }^{50}$ In Italy, $94 \%$ of gastroenterologists in one survey reported practicing defensive medicine, with $18 \%$ of endoscopies, $12 \%$ of consultations, and $9 \%$ of abdominal ultrasound examinations reported to be defensively motivated. ${ }^{51}$ Also within Italy, one study found that $78 \%$ of general practitioners and $83 \%$ of surgeons and anesthesiologists reported practicing defensive medicine in the past month. ${ }^{52}$ In a survey of orthopedic surgeons, trauma surgeons, and radiologists in Austria, the overall prevalence of defensive medicine was $98 \%$, with the average surgeon surveyed requesting nearly 20 investigations each month for defensive reasons. ${ }^{53}$ The time spent performing defensively motivated interventions or studies was reported to be approximately $18 \%$ of total work hours among surgeons. Finally, in a survey of Japanese gastroenterologists, 91\% reported providing additional services of marginal or no medical value to reduce the risk of liability, and $96 \%$ reported avoiding certain procedures among high risk patients for the same reason. ${ }^{54}$ Although these and other studies demonstrate similarities in defensive medicine between physicians in the US and other countries, less published evidence exists on the cause of malpractice claims across countries. For example, in a recent systematic review of the epidemiology of malpractice claims in primary care, published evidence on the cause of such claims was only available in the US, Australia, UK, and Canada.. ${ }^{21}$ Across these countries, diagnostic error was the leading cause of malpractice. Notably, however, an analysis of 18907 complaints by patients in Australia alleged communication problems in a sizeable percentage of claims ( $23 \%$ v 41\% related to diagnostic error). ${ }^{22}$

\section{Strengths and limitations of this study}

Our study has several limitations. Firstly, a principal limitation was that the association between resource use by physicians and malpractice claims may be confounded by unmeasured illness severity of patients. It is possible that physicians with higher adjusted hospital charges are those who treat patients with greater unmeasured illness severity and thus are at higher risk of adverse outcomes. However, we would expect that these unobserved factors would bias toward a positive association between average physician spending and malpractice claims, rather than the negative association that we found. Secondly, though we found that physicians with higher average spending face fewer malpractice claims, we do not know whether higher spending is defensively motivated-that is, is driven by a desire to reduce malpractice liability, or whether it reflects other idiosyncratic factors such as a physician's proclivity to order tests, procedures, and consultations, or varying risk aversion among physicians. None the less, the empirical association that we observed between physician level spending and risk of subsequent malpractice claims is consistent with physicians' beliefs about the impact of defensive medicine, and it further highlights one reason why efforts to curb physician spending have been challenging. Thirdly, our approach to classifying the intensity of care provided by physicians relied on hospital data rather than on outpatient data. A more accurate representation of physician practice patterns and the correlation of those patterns with malpractice claims would rely on both outpatient and inpatient data. However, physician hospital costs are still a useful measure of physician resource use because, in national data, nearly half of all paid malpractice claims are for incidents occurring in the inpatient setting, ${ }^{55}$ with a larger proportion related to inpatient incidents among surgeons. ${ }^{56} 57$ Also, further supporting our approach, it has been argued that hospital care may be more subject to defensive medicine than outpatient care since the latter more often entails longitudinal patient relationships. ${ }^{58} \mathrm{~A}$ fourth limitation is that we attributed resource use patterns in a given hospital admission to the attending physician of record, which may be imperfectly recorded. This error biases our measured relation between resource use and malpractice claims toward zero. Fifthly, our sample was not nationally representative, but the rates of malpractice claims that we observed within specialty were similar to a national analysis of malpractice risk according to physician specialty. ${ }^{41}$ Sixthly, we linked information between two administrative databases and this could have resulted in imperfect matches. However, as long as match failure is uncorrelated with physician spending this would not affect our findings. Seventhly, we focused our findings on resource use and did not consider the relation between avoidance medicine-that is, avoiding patients perceived to represent high liability risk, also called "negative defensive medicine"-with a lower risk of malpractice. ${ }^{59}$ For example, in a survey of UK general practitioners, 80\% cited growing liability insurance fees as a primary reason for reducing the 
number of off-hours shifts worked. ${ }^{60}$ Moreover, in a survey of UK hospital doctors, 9\% reported that they refused to treat high risk patients and 21\% reported avoiding high risk procedures. ${ }^{15}$ Also, because our data relied on hospital charges and not paid amounts, we could not directly estimate the association between a given increase in healthcare expenditures and risk of malpractice. Finally, to the extent that our findings indicate a causal relation-meaning that higher resource use directly lowers the risk of malpractice-we do not know whether that is because patients receiving more resource use experience better outcomes and have less cause to sue, or whether outcomes are the same and the additional care simply wards off lawsuits. Further work should seek to identify the mechanisms through which additional resource use lowers the risk of malpractice claims.

\section{Conclusions}

Despite evidence that the majority of US physicians report practicing defensive medicine, no evidence exists on the broader question of whether greater resource use by physicians is associated with fewer malpractice claims. Our findings suggest that greater resource use, whether it reflects defensive medicine or not, is associated with fewer malpractice claims.

Contributors: All authors contributed to the design and conduct of the study; data collection, management, analysis, and interpretation; and preparation, review, or approval of the manuscript. AB) is the guarantor. The research conducted was independent of any involvement from the sponsors of the study. Study sponsors were not involved in study design, data interpretation, writing of the manuscript, or the decision to submit the article for publication. Funding: This study was supported by the Office of the Director, National Institutes of Health (NIH early independence award, grant 1DP50D017897-01 to ABJ) and National Institute of Aging (R37 AG036791 to JB)

Competing interests: All authors have completed the ICMJE uniform disclosure form at www.icmje.org/coi_disclosure.pdf (available on request from the corresponding author) and declare; no financial relationships with any organisations that might have an interest in the submitted work in the previous three years; no other relationships or activities that could appear to have influenced the submitted work.

Ethical approval: The study was exempt from human subjects ethics review at Harvard Medical School.

Data sharing: No additional data available.

Transparency: The lead author (ABJ) affirms that the manuscript is an honest, accurate, and transparent account of the study being reported: that no important aspects of the study have been omitted; and that any discrepancies are disclosed.

This is an Open Access article distributed in accordance with the Creative Commons Attribution Non Commercial (CC BY-NC 4.0) license, which permits others to distribute, remix, adapt, build upon this work non-commercially, and license their derivative works on different terms, provided the original work is properly cited and the use is non-commercial. See: http://creativecommons.org/licenses/ by-nc/4.0/.

1 Studdert DM, Mello MM, Sage WM, et al. Defensive medicine among high-risk specialist physicians in a volatile malpractice environment. JAMA 2005:293:2609-17.

2 Hermer LD, Brody H. Defensive medicine, cost containment, and reform. J Gen Intern Med 2010;25:470-3.

3 Carrier ER, Reschovsky JD, Mello MM, Mayrell RC, Katz D. Physicians' fears of malpractice lawsuits are not assuaged by tort reforms. Health affairs 2010;29:1585-92.

4 Bishop TF, Federman AD, Keyhani S. Physicians' views on defensive medicine: a national survey. Arch Intern Med 2010;170:1081-3.

5 Rothberg MB, Class J, Bishop TF, Friderici J, Kleppel R, Lindenauer PK. The cost of defensive medicine on 3 hospital medicine services. JAMA Intern Med 2014;174:1867-8.
6 Investigation of Defensive Medicine in Massachusetts. 2008. www. ncrponline.org/PDFs/2008/Mass_Med_Soc.pdf.

Baicker K, Chandra A. The effect of malpractice liability on the delivery of health care. BE Press Forum for Health Economics and Policy 2006;8.

8 Baicker K, Fisher ES, Chandra A. Malpractice liability costs and the practice of medicine in the Medicare program. Health Aff (Millwood) 2007;26:841-52

9 Kessler DP, McClellan MB. Do doctors practice defensive medicine? Q/Econ 1996:111:353-90.

10 Kessler DP, McClellan MB. How liability law affects medical productivity. J Health Econ 2002;21:931-55.

11 Dubay L, Kaestner R, Waidmann T, Health Policy Center UIWDCUSAluuo. The impact of malpractice fears on cesarean section rates. J Health Econ 1999;18:491-522.

12 Lakdawalla DN, Seabury SA. The welfare effects of medical malpractice liability. Int Rev Law Econ 2012;32:356-69.

13 Chandra A, Jena AB, Seabury S. Defensive medicine may be costlier than it seems. Wall Street Journal 2013 Feb 7.

14 Mello MM, Chandra A, Gawande AA, Studdert DM. National costs of the medical liability system. Health affairs 2010;29:1569-77.

15 Ortashi O, Virdee J, Hassan R, Mutrynowski T, Abu-Zidan F. The practice of defensive medicine among hospital doctors in the United Kingdom. BMC Med Ethics 2013;14:42.

16 Levinson W, Roter DL, Mullooly JP, Dull VT, Frankel RM. Physicianpatient communication. The relationship with malpractice claims among primary care physicians and surgeons. JAMA 1997;277:553-9.

17 Beckman HB, Markakis KM, Suchman AL, Frankel RM. The doctor-patient relationship and malpractice. Lessons from plaintiff depositions. Arch Intern Med 1994;154:1365-70.

18 Vincent C, Young M, Phillips A. Why do people sue doctors? A study of patients and relatives taking legal action. Lancet 1994;343:1609-13.

19 Hickson GB, Clayton EW, Githens PB, Sloan FA. Factors that prompted families to file medical malpractice claims following perinatal injuries. JAMA 1992;267:1359-63.

20 Saber Tehrani AS, Lee H, Mathews SC, et al. 25-Year summary of US malpractice claims for diagnostic errors 1986-2010: an analysis from the National Practitioner Data Bank. BMJ Qual Saf 2013;22:672-80.

21 Wallace E, Lowry J, Smith SM, Fahey T. The epidemiology of malpractice claims in primary care: a systematic review.BMJ Open 2013;3.

22 Bismark MM, Spittal MJ, Gurrin LC, Ward M, Studdert DM. Identification of doctors at risk of recurrent complaints: a national study of healthcare complaints in Australia. BMJ Qual Saf 2013;22:532-40.

23 Newman-Toker DE, Pronovost PJ. Diagnostic errors-the next frontier for patient safety. JAMA 2009;301:1060-2.

24 Graber ML, Franklin N, Gordon R. Diagnostic error in internal medicine. Arch Intern Med 2005;165:1493-9.

25 Volpintesta E. Administrative overload as a cause of diagnostic error. IAMA Intern Med 2013;173:1927.

26 Localio AR, Lawthers AG, Brennan TA, et al. Relation between malpractice claims and adverse events due to negligence. Results of the Harvard Medical Practice Study III. N Engl J Med 1991;325:245-51.

27 Brennan TA, Sox CM, Burstin HR. Relation between negligent adverse events and the outcomes of medical-malpractice litigation. N Engl J Med 1996;335:1963-7.

28 Studdert DM, Mello MM, Gawande AA, et al. Claims, errors, and compensation payments in medical malpractice litigation. N EnglJ Med 2006;354:2024-33.

29 Weiler PC, Hiatt HH, Newhouse JP, Johnson WG, Brennan TA, Leape LL. A measure of malpractice: medical injury, malpractice litigation, and patient compensation. Harvard University Press; 1993.

30 McClellan M, McNeil BJ, Newhouse JP. Does more intensive treatment of acute myocardial infarction in the elderly reduce mortality? Analysis using instrumental variables. JAMA 1994;272:859-66.

31 Wennberg J, Gittelsohn. Small area variations in health care delivery. Science 1973;182:1102-8.

32 Fisher ES, Wennberg DE, Stukel TA, Gottlieb DJ, Lucas F, Pinder EL. The implications of regional variations in Medicare spending: Part 2. Health outcomes and satisfaction with care. Landmark Papers in Internal Medicine: The First 80 Years of Annals of Internal Medicine 2009:30.

33 Romley JA, Jena AB, O'Leary JF, Goldman DP. Spending and mortality in US acute care hospitals. Am J Manag Care 2013;19:e46-54.

34 Jena AB, Prasad V, Goldman DP, Romley J. Mortality and treatment patterns among patients hospitalized with acute cardiovascular conditions during dates of national cardiology meetings. JAMA Intern Med 2015;175:237-44.

35 Entman SS, Glass CA, Hickson GB, Githens PB, Whetten-Goldstein K, Sloan FA. The relationship between malpractice claims history and subsequent obstetric care. JAMA 1994:272:1588-91.

36 Localio AR, Lawthers AG, Bengtson JM, et al. Relationship between malpractice claims and cesarean delivery. Jama 1993;269:366-73.

37 Gimm GW. The impact of malpractice liability claims on obstetrical practice patterns. Health Serv Res 2010;45:195-211. 
38 Yang YT, Mello MM, Subramanian SV, Studdert DM. Relationship between malpractice litigation pressure and rates of cesarean section and vaginal birth after cesarean section. Med Care 2009:47:234-42.

39 Seabury SA, Chandra A, Lakdawalla DN, Jena AB. On average, physicians spend nearly 11 percent of their 40 -year careers with an open, unresolved malpractice claim. Health Aff (Millwood) 2013;32:111-9.

40 Jena AB, Schoemaker L, Bhattacharya J. Exposing physicians to reduced residency work hours did not adversely affect patient outcomes after residency. Health Aff (Millwood) 2014:33:1832-40.

41 Jena AB, Seabury S, Lakdawalla D, Chandra A. Malpractice risk according to physician specialty. N Engl / Med 2011;365:629-36.

42 Osterman MJ, Martin JA. Trends in low-risk cesarean delivery in the United States, 1990-2013. Natl Vital Stat Rep 2014;63:1-16.

43 Specifications Manual for Joint Commission National Quality Measures, table No 11.09: contraindications to vaginal delivery. 2014. https://manual.jointcommission.org/releases/TJC2014A/ AppendixATJC.html\#Table_Number_11_09_Contraindicat.

44 Spiegelhalter DJ, Abrams KR, Myles JP. Bayesian approaches to clinical trials and health-care evaluation. Wiley; 2004

45 Copas JB. Regression, Prediction and shrinkage. I R Stat Soc Ser B 1983; $45: 311-54$

46 Jena AB, Chandra A, Lakdawalla D, Seabury S. Outcomes of medical malpractice litigation against US physicians. Arch Intern Med 2012;172:892-4

47 Romley JA, Jena AB, Goldman DP. Hospital spending and inpatient mortality: evidence from California: an observational study. Ann Intern Med 2011;154:160-7.

48 Greenberg MD, Haviland A, Ashwood JS, Main R. Is better patient safety associated with less malpractice activity? Evidence from California; 2010. Available at www.rand.org/pubs/technical reports/ TR824.html.

49 Summerton N. Positive and negative factors in defensive medicine: a questionnaire study of general practitioners. BMJ 1995;310:27-9.
50 Summerton N. Trends in negative defensive medicine within general practice. BrJ Gen Pract 2000;50:565-6.

51 Elli L, Tenca A, Soncini M, Spinzi G, Buscarini E, Conte D. Defensive medicine practices among gastroenterologists in Lombardy: between lawsuits and the economic crisis. Dig Liver Dis 2013;45:469-73.

52 Catino M. Celotti S. The problem of defensive medicine: two Italian surveys. Stud Health Technol Inform 2009;148:206-21.

53 Osti M, Steyrer J. A national survey of defensive medicine among orthopaedic surgeons, trauma surgeons and radiologists in Austria: evaluation of prevalence and context. I Eval Clin Pract 2015;21:278-84

54 Hiyama T, Yoshihara M, Tanaka S, et al. Defensive medicine practices among gastroenterologists in Japan. World I Gastroenterol 2006;12:7671-5

55 Bishop TF, Ryan AM, Casalino LP. Paid malpractice claims for adverse events in inpatient and outpatient settings. JAMA 2011;305:2427-31.

56 Rogers SO Jr, Gawande AA, Kwaan M, et al. Analysis of surgical errors in closed malpractice claims at 4 liability insurers. Surgery 2006;140:25-33.

57 Regenbogen SE, Greenberg CC, Studdert DM, Lipsitz SR, Zinner MI, Gawande AA. Patterns of technical error among surgical malpractice claims: an analysis of strategies to prevent injury to surgical patients. Ann Surg 2007;246:705-11.

58 Schaffer AC, Puopolo AL, Raman S, Kachalia A. Liability impact of the hospitalist model of care. J Hosp Med 2014;9:750-5.

59 Carrier ER, Reschovsky JD, Katz DA, Mello MM. High physician concern about malpractice risk predicts more aggressive diagnostic testing in office-based practice. Health Aff (Millwood) 2013:32:1383-91.

60 Kmietowicz Z. Eight in 10 GPs say indemnity fees are limiting their out-of-hours work. BMJ 2015:351:h4549.

Web appendix: supplementary information 